\title{
A Review of Football Injuries and the Role of 3D Biomechanical Analysis in Injury Prevention
}

\author{
Arumugam Sivaraman ${ }^{1}$, Janani Gopalakrishnan ${ }^{2}$, Keddin Alwar Thiagarajan $^{3}$, Suresh Perumal ${ }^{4}$, Prakash Ayyadurai $^{5}$, \\ Utkarsh Singh 6
}

\begin{abstract}
Background: Football is the world's most popular game and is rapidly growing in India. Lower limb injuries are a major concern. Applied research in Indian football scenario is required to prevent injuries and enhance performance of the players to take India higher up in FIFA world ranking. Aim: This review aims to concise common lower limb injuries in football and understand the biomechanics of the football kick particularly from the injury risk point of view as well as performance.

Review results: Approximately $60-80 \%$ of severe injuries to football players occur in the lower extremities, most commonly at the thigh muscles $(30 \%)$, knee (29\%), foot and ankle (11-23\%), and groin (8-18\%). Biomechanics deals with analysis of human body movements. A combination of spatial dimension analysis (2D or 3D), surface electromyography, and force plate analysis can identify the cause of injury and aid in its prevention while providing information on performance enhancement techniques in addition.

Conclusion: Football injuries are widely prevalent with lower limb being the most affected. The game of football is growing in India and injuries are becoming increasingly common affecting the player's career and team's performance. The biomechanics analysis of instep kick provides vital inputs into the injury risk and performance enhancement.

Clinical significance: The biomechanical analysis of the football instep kicking action using 3D motion capture, force plates, electromyography (EMG), and applying the data to modify techniques will help in injury prevention and performance enhancement.

Keywords: 3D motion capture, Biomechanics, Electromyography, Football injury, Force plate, Injury prevention, Return to play.

Journal of Postgraduate Medicine, Education and Research (2020): 10.5005/jp-journals-10028-1420
\end{abstract}

\section{BACKGROUND}

Football is the world's most popular game both in terms of participants and spectators. Football's governing body, the Fédération Internationale de Football Association (FIFA), estimated that at the turn of the twenty-first century there were approximately 250 million football players and over 1.3 billion people interested in football. Football in India is the second most watched sport after cricket and has a well-designed league system constituting the Indian Super League, I-League, Second division leagues, and Youth leagues. Even after half a century of being recognized by FIFA, India still hovers around 100th position out of 210 nations in the world rankings. ${ }^{1}$ This plight of Indian football can be attributed to the lack of scientific approach to techniques, strength training programs, and injury prevention strategies along with imbalance between technical and tactical training. This has mandated an applied research to be carried out in Indian football scenario with the aim to prevent injuries and enhance performance.

\section{Literature Review}

The football kick is characterized by a proximal-to-distal sequencing of lower limb segments along with trunk motions. There is a dynamic arc formation in the kicking leg through various phases of kicking, which correlates to the kick quality. ${ }^{2}$ Injuries to the lower limb are a major concern since it leads to a significant loss of play time in a player's career. The aim of this review is to concise the most common lower limb injuries in football and understand the biomechanics of the football kick particularly from the injury risk point of view as well as performance.

\footnotetext{
${ }^{1-5}$ Department of Arthroscopy and Sports Medicine, Sri Ramachandra Medical College and Research Institute, Chennai, Tamil Nadu, India

${ }^{6}$ Department of Biomechanics, Faculty of Sports and Exercise Sciences, Sri Ramachandra Institute of Higher Education and Research, Chennai, Tamil Nadu, India
}

Corresponding Author: Keddin Alwar Thiagarajan, Department of Arthroscopy and Sports Medicine, Sri Ramachandra Medical College and Research Institute, Chennai, Tamil Nadu, India, Phone: +91 9444415744, e-mail: drkatn@csstrucoach.in

How to cite this article: Sivaraman A, Gopalakrishnan J, Thiagarajan $\mathrm{KA}$, et al. A Review of Football Injuries and the Role of 3D Biomechanical Analysis in Injury Prevention. J Postgrad Med Edu Res 2020;54(4): 206-212.

Source of support: Nil

Conflict of interest: None

\section{Physical Demands of Football}

Football consists of sprinting, kicking, passing, heading, and cutting maneuvers. Kicking action is given utmost importance as it is used maximally throughout the game but it is also a major cause for injury. Regaining the ability to kick is essential for football players to return to play after injury. During an average 90 -minute game, a player has 51 contacts with the ball, 26 with the foot. ${ }^{3}$ An analysis of injury risk while playing football indicated that kicking accounted for $51 \%$ of potential actions that could lead to injury. ${ }^{4}$ Kicking is the most reproducible action in football.

Football players are at risk for injury, especially to the lower extremity and at the knee. The incidence of football-related injuries

(c) The Author(s). 2020 Open Access This article is distributed under the terms of the Creative Commons Attribution 4.0 International License (https://creativecommons. org/licenses/by-nc/4.0/), which permits unrestricted use, distribution, and non-commercial reproduction in any medium, provided you give appropriate credit to the original author(s) and the source, provide a link to the Creative Commons license, and indicate if changes were made. The Creative Commons Public Domain Dedication waiver (http://creativecommons.org/publicdomain/zero/1.0/) applies to the data made available in this article, unless otherwise stated. 


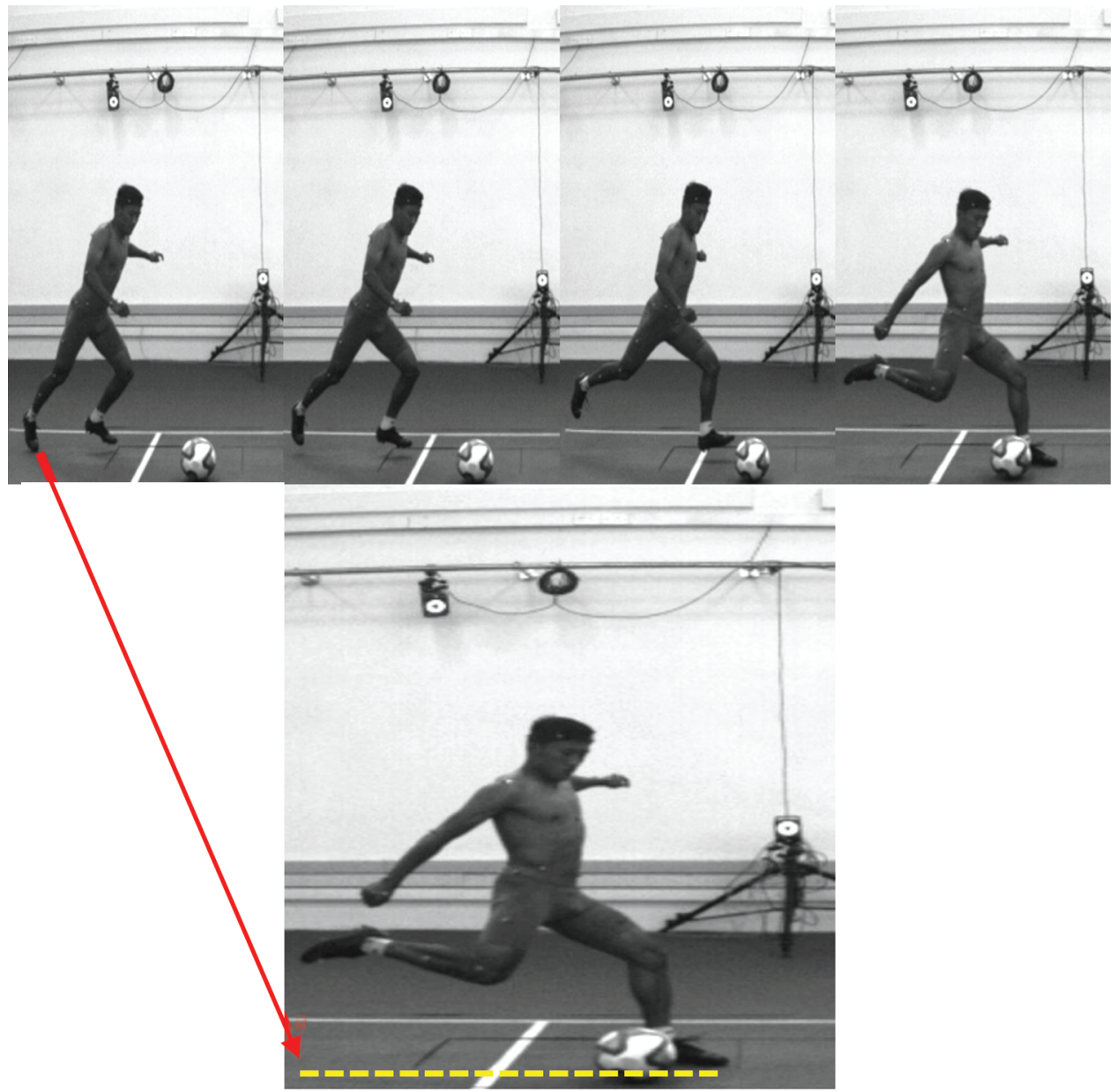

Fig. 1: The five phases of football kick in 2D and 3D motion capture (Images courtesy: Centre for Sports Science, Sri Ramachandra Institute of Higher Education and Research, Chennai)

is estimated to be $10-35$ per 1,000 playing hours in adult male players $^{5}$ and often higher in younger and less-skilled players. ${ }^{6}$ Approximately $60-80 \%$ of severe injuries to football players occur in the lower extremities, most commonly at the thigh (up to $30 \%$ ), knee (29\%), and ankle (19\%). ${ }^{7}$ The most serious and frequent injuries occur to the anterior cruciate ligament, posterior cruciate ligament, and medial collateral ligament.

\section{Football Kicking Action}

The football kick can be classified into several types based on the player's approach and the anatomical region of the foot coming in contact with the ball, namely the side foot kick, instep kick, toe kick, push kick, and heel kick. The two main techniques used according to the analysis of goals in men's World Cup are the side foot kick, which strikes the ball with the medial aspect of the midfoot, and the instep kick, which strikes the ball with the dorsum of the foot. The most common kick used for maximal force generation is the instep kick. ${ }^{8}$ The free kick in football including the penalty kick is a tensionfilled task and almost always a deterministic moment of a game.

Brophy et al. defined five phases consisting of six events in an instep football kick including preparation or approach, backswing, leg cocking, acceleration, and follow-through. The duration of the entire kick cycle ranges between 0.65 and 0.83 seconds in elite players $^{8}$ (Figs 1, 2 and Table 1).

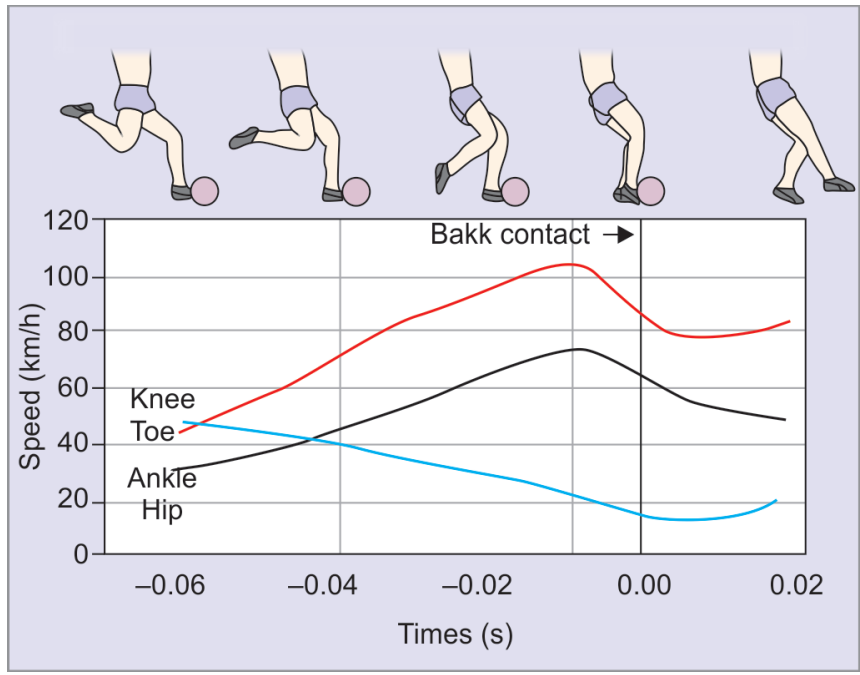

Fig. 2: Kinetic data analysis during the five phases of football

\section{FoOTBALL INJURIES}

\section{Injuries to Thigh Muscles}

Thigh muscle injuries are often a result of contusions and muscle strains due to repeated maximal sprints and accelerations. Football 
Table 1: The five phases of football kick

\begin{tabular}{|c|c|}
\hline Phases & Events \\
\hline 1. Approach & From heel strike to toe-off \\
\hline 2. Backswing & From toe-off to maximal hip extension \\
\hline 3. Leg cocking & $\begin{array}{l}\text { From maximal hip extension to maximal knee } \\
\text { flexion }\end{array}$ \\
\hline 4. Acceleration & From maximal knee flexion to ball contact \\
\hline 5. Follow-through & $\begin{array}{l}\text { From ball contact to toe velocity inflection or } \\
\text { maximum knee extension }\end{array}$ \\
\hline
\end{tabular}

involves a combination of maximal sprints with frequent playerto-player contact, and hence, up to $30 \%$ of all football injuries are found to be thigh muscle injuries. On an average, a male elite-level football team with a squad of 25 players can expect around 18 muscle injuries per season. ${ }^{9}$ Of these, seven will affect hamstrings and three will affect quadriceps. Muscle contusion injuries to the thigh account for up to $16 \%$ of all acute football injuries at the elite level. In young players, the most common muscle injury is the tear of rectus femoris muscle, whereas in professional football players hamstring muscles are involved more. Due to the magnitude of the problem, a need for a better understanding of muscle injuries and their prevention has become an emerging challenge for football clubs. An injury is classified by mechanism of injury (M), location $(L)$, grading by imaging, and whether there has been a reinjury $(R)$. Using this "MLG-R," it should be possible to classify muscle injuries in groups with similar functional impairment and prognosis. ${ }^{10}$

\section{Injuries of the Knee}

The knee is one of the most common locations for injury in football players (second only to the thigh). While anterior cruciate ligament $(\mathrm{ACL})$ injuries represent less than $1 \%$ of all injuries, their impact on a player's career is very significant. ${ }^{11}$ As a result, these injuries are well known and widely publicized. The injury generally does not involve a significant trauma and is "non-contact." A randomized controlled study has compared the nonoperative and surgical treatment of this injury. ${ }^{12}$ At 5-year follow-up, the patients had no differences in their ability to return to sport, reported knee function, or rate of meniscal injury. Approximately $50 \%$ of those who were treated nonsurgically subsequently required an $A C L$ reconstruction surgery. ${ }^{12}$

Meniscal tears represent $8 \%$ of all injuries sustained over a professional football season. The medial meniscus is affected in more than $70 \%$ of the cases. ${ }^{13}$ Focal articular cartilage defects of the knee are also a substantial cause of pain and disability in active football players predisposing them to further joint deterioration and eventually osteoarthritis. Focal chondral defects have been noted in up to $63 \%$ of patients undergoing arthroscopy of the knee in the general population and are observed with increasing frequency in the athletic population. ${ }^{14}$ Cartilage injuries are most commonly seen in female players, older players, and players with a history of a previous knee injury.

\section{Foot and Ankle Injuries}

Between 2 and 9.4 football players suffer an injury to their feet per 1,000 hours of exposure. ${ }^{15}$ Commonly found are sprains, fractures, and torn ligaments as well as various blows and bruises. A higher proportion of foot injuries in football occur as the result of foul play and tackles. The severity of injury where the player is weight-bearing is generally higher than that observed for the nonweight-bearing foot. ${ }^{15,16}$ Turf toe, metatarsal fractures, Lisfranc injuries, navicular fractures, stress fractures, hallux rigidius, bunions, plantar fasciitis, sesamoiditis, Morton's neuroma, hammertoe, and metatarsophalangeal joint (MTPJ) instability are the commonly found foot conditions in the football.

Ankle injuries constitute $11-23 \%$ of all injuries recorded during FIFA competitions. The rate of ankle injuries in lower-level amateur players, children, and adolescents is higher still, representing $35 \%$ of all injuries. ${ }^{17}$ Most ankle injuries are relatively uncomplicated sprains of the lateral ligament complex. Lateral ligament sprains and acute peroneal tendon injuries generally occur after an ankle inversion injury. Inversion may occur when cutting, running on uneven ground, or landing on an opponent's foot. Deltoid ligament injuries typically occur after ankle eversion. Syndesmosis injuries generally occur with forced dorsiflexion, forced external rotation of the foot, or after eversion of the talus. Past history of ankle injury poses a major risk factor. The ligaments usually tear in sequence, ${ }^{18}$ starting with the anterior talofibular ligament (ATFL) progressing to involve the more posterior calcaneofibular (CFL) and posterior talofibular ligaments. The Ottawa ankle rules are generally followed to decide on the course of management regarding taking the player off the football field for radiological testing.

Fractures around the ankle mortise, lateral process of talus, anterior process of calcaneum, maisonneuve fracture, and stress fractures of distal tibia and fibula have been documented in football. Anterior ankle impingement occurs due to repeated contact during extremes of dorsiflexion during kicking and posterior impingement due to a prominent posterior process of the talus or os trigonum. Soft tissue causes of impingement include synovial hypertrophy, capsular injury, ligament injury, and flexor hallucis longs (FHL) tenosynovitis or tendinitis. Cartilaginous injuries of the talar dome, peroneal injuries, tibialis posterior tendon disorders, and Achilles rupture are few other notable conditions of ankle.

\section{Groin Injuries}

Groin injuries are among the three most common and timeconsuming injuries in Football, accounting for $8-18 \%$ of all injuries and with an incidence of $0.4-1.3$ injuries per 1,000 hours of a Football play. ${ }^{19}$ An unanimous agreement in 2014-the Doha agreement-was reached on the following classification system in which groin pain in players is described under three major subheadings: $:^{20}$

- Defined clinical entities for groin pain

- Adductor-related

- lliopsoas-related

- Inguinal-related

- Pubic-related groin pain

- Hip-related groin pain

- Other causes of groin pain

Anderson et al. concluded that from a biomechanical perspective, the highest risk of groin injury occurs during the backswing and leg cocking phases, where the hip and groin muscles work eccentrically at high intensity and velocity. ${ }^{21}$ With a large incidence of groin injuries, prevention is very valuable. However, a systematic review found no study showed a statistically significant value of the prevention programs examined. ${ }^{22}$

\section{Stress Fractures of Lower Limb}

Stress fractures may result from: ${ }^{23}$

- An increase in the applied load or the number of applied stresses

- Inadequate recovery time between sessions or

- Application of normal loads to weakened bones 
Other risk factors may include inadequate calcium or caloric intake; hormonal factors such as menstrual disturbance in females or reduced testosterone in males; osteoporosis, decreased bone density, or bone geometry; muscle weakness; and leg-length differences. ${ }^{24} \mathrm{~A}$ significant published work on stress fractures in footballers was done between 2001 and 2009 in 54 elite teams (involving 2,379 players), ${ }^{25}$ which identified 51 stress fractures in 40 players, all involving the lower limb. This equates to a risk of $0.04 / 1,000$ player hours of exposure. These injuries are responsible for significant time loss. Stress fractures were more common in preseason and in younger players. All but three injuries were considered severe (absence $>28$ days) and the mean return to sport was approximately 3 months (to 5 months for pelvic stress fractures). There was also a high $29 \%$ risk of recurrence of all the reported fractures involved in the lower limb. ${ }^{25}$

\section{Tendinopathy}

In professional football, the incidence of both patellar tendinopathy and Achilles tendinopathy is more common during the preseason than during the competitive season. This may reflect a sudden increase in training volumes - or a greater overall training volume. While these conditions only represent $2.5 \%$ of all injuries, they represent between 20 and $27 \%$ of all reinjuries. Tendon disorders comprise $30-50 \%$ of all sports-related injuries ${ }^{26}$ and there is a lifetime risk of $52 \%$ that elite long-distance runners will suffer from an Achilles tendon injury. ${ }^{27}$ Tendinopathies generally go through phases of pathology, namely reactive tendinopathy, tendon disrepair, and degenerative tendinopathy. ${ }^{28}$ Timely diagnosis and intervention at each phase save the player from further complications (Table 2).

\section{Biomechanical Analysis of Football}

Biomechanics deals with physical analysis of human body movements. With the advances in the field of sports movement analysis, the cause of injury can be determined, and progress of rehabilitation monitored. Commonly employed methods include spatial dimension analysis (2D or 3D), motion analysis with electromyography (EMG) measurement, and force plate analysis.

\section{D Video Analysis}

2D motion capture studies were performed as early as the $1960 \mathrm{~s}^{29}$ and continued to be the mainstay analysis up until the 2000s when the $3 \mathrm{D}$ analysis was introduced. The $2 \mathrm{D}$ analysis of the football instep technique was used to quantify the ball speed, joint angles, and angular velocity. Most of the results delivered have been limited to the partial body analysis in the sagittal plane. In terms of injury prevention, one risk factor found among inexperienced players was the contact location between foot and ball. While the ball

Table 2: Incidence of lower limb injuries in football

\begin{tabular}{lll}
\hline Lower limb injury & Incidence (\%) & References \\
\hline Thigh & Up to 30 & 7 \\
$\begin{array}{l}\text { Knee (ligamentous } \\
\text { complex, patella) }\end{array}$ & Up to 29 & 7 \\
Foot and ankle & $11-23$ & \\
Groin & $8-18$ & 7,17 \\
Hip & $<5$ & 19 \\
Tendinopathy & 2.5 & 19 \\
Stress fractures & $0.5-1.8$ & 26 \\
\hline
\end{tabular}

is hit correctly by professionals (dorsal arch area of the foot), the amateurs or sometimes even the advanced players meet the ball more with the front part of the foot. ${ }^{30}$ Such kicks lead often to an injury caused by rapid overextension of the foot and result also in a reduced ball speed. It is recommended that training should begin with a slow leg swing, concentrating on kick accuracy. Only when there is a high degree of accuracy achieved, training can forward with an increased swing leg motion. ${ }^{31}$

\section{D Motion Capture and Kinematic Analysis}

Full-body biomechanics of each and every phase of football kick can be studied in detail using 3D motion capture systems. Nearly all studies are limited to examining only the kicking leg. This is mainly due to the difficulty involved in tracking high-speed, relatively unpredictable movements in a large capture volume when using a full-body kinematic model. ${ }^{32} \mathrm{~A}$ few researchers used an optoelectronic system at $100 \mathrm{~Hz}$ for recording marker positions strategically placed on the leg joints in $3 \mathrm{D} .{ }^{33}$ Their results however did not reveal new aspects of the instep technique when compared to the 2D studies that were previously performed. The first fullbody 3D analysis of the instep technique was performed by Shan and Westerhoff. ${ }^{34}$ A nine-camera VICON motion analysis system tracked motion of the kicker with a full-body model consisting of 42 reflective markers @ $120 \mathrm{~Hz}$ and 3 markers over the football ball. Results revealed that the key characteristics of the in-step technique could be extracted as the formation of a tension arc, and the fast release of this tension arc in a quasi-whip-like fashion with complimentary upper body movement. This finding was original in that the upper body had never been examined and thus the tension arc modeled from previous studies ended at the player's hip. Furthermore, by comparing different levels of players, Shan and Westerhoff confirmed that the tension arc created by the kicking leg and upper body generated an explosive muscle contraction through muscle prelengthening in the backswing, increasing the power of the kick. This prelengthening forms the basis for increased groin injuries in football. They concluded that the maximal distance between the hip of the kicking leg and the opposite shoulder provided a quantitative means to judge kick quality, therefore demonstrating that the full-body 3D analysis may be more advantageous when compared to the 2D model for studying the instep technique. It was found that more skilled players demonstrated much greater range of motion in both the hip and knee joints, which lead to higher foot velocity. However, a novice kicker used the knee as the primary source of inertia for creating foot velocity. ${ }^{34}$ This suggests that there are more factors than just knee extension, such as flexibility and timing of body segment movement as in the "Summation of Speed Principle," making up an effective instep kick.

\section{Surface Electromyographic Studies}

Electromyography has been used to examine muscle activity during an instep kick to help explain the role of a muscle through the kick. It offers a means to acquire in vivo data about muscle processes with a noninvasive approach. In the studies presented, all values are expressed as a percentage of the EMG recorded with regards to the maximum voluntary contraction (MVC) for each muscle. Using this method to examine muscle excitation through an instep kick gives very useful information on the timing of muscle activation through the kick and as a result of which muscles contribute to a player's kicking performance. This information could be used for specific muscle training. It can also be used to point out areas of high stress 
and potentially assist in injury prevention. Several studies employed EMG measurement in an attempt to characterize activation, coordination, and intensity of selected muscles during football kicking. ${ }^{35,36}$ But there is a concern of using EMG measurement alone in an application, as it lacks the connection between body's movement and neural muscle contractions. Therefore, some researchers have synchronized EMG data with 2D motion analysis in order to link muscle activities to joint kinematics for more accurate analyzes. ${ }^{8}$ By investigating muscle activity changes of iliacus, gluteus maximus, gluteus medius, vastus lateralis, vastus medialis, hamstrings, gastrocnemius, hip adductors, and tibialis anterior, the research found that significant interaction existed between the hamstrings and the tibialis anterior. Additionally, as expected, higher muscle loading was found in kicking leg, as the activation of iliacus, vastus medialis, gastrocnemius, and hip adductors was significantly larger than those in the nonkicking side. ${ }^{8}$ Watanabe et al. analyzed the adductor components of both the kicking and supporting legs and concluded that adductor magnus muscle plays a marked role to intensify the instep kicking motion. ${ }^{37}$ Electromyography reading during accuracy kicking to the top-right corner of the goal demonstrated highest quadriceps EMG level than those toward the rest corners. This suggested that a top-right instep kick would be the most powerful kick for accelerating the ball and would leave less time for goalkeepers to react. ${ }^{32}$ Integrating EMG with $2 \mathrm{D}$ and $3 \mathrm{D}$ data would provide a holistic approach toward body control in football.

\section{Kinetic Analysis Using Force Plates}

Optimal ground reaction force (GRF) of the support leg is needed for trunk rotation and transfer of kinetic energy to the kicking leg. Higher GRF would lead to knee and lower back injuries. The study of joint reaction forces by the principle of inverse dynamics helps to study the injuries at the load-bearing joints like ankle and knee (Fig. 3).

\section{Discussion}

\section{Injury Prevention Strategies}

The scientific assessment using the biomechanical concepts will be an added advantage to the already documented injury prevention strategies. One of the most widely followed such strategy, named FIFA 11+ prevention program, has a substantial injury-preventing effect by reducing football injuries by $39 \% .{ }^{38}$ Adoption and implementation of the $\mathrm{NH}$ exercise program has positive effects in hamstring injury prevention. ${ }^{39}$ Intervention program consisting of football-specific landing skills aids in prevention of lower limb injuries. ${ }^{40}$ Eccentric lower limb injury prevention exercises with proper periodization. ${ }^{41}$ Neuromuscular control training exercises reduces knee injuries by $50 \%{ }^{42}$ Strength training for
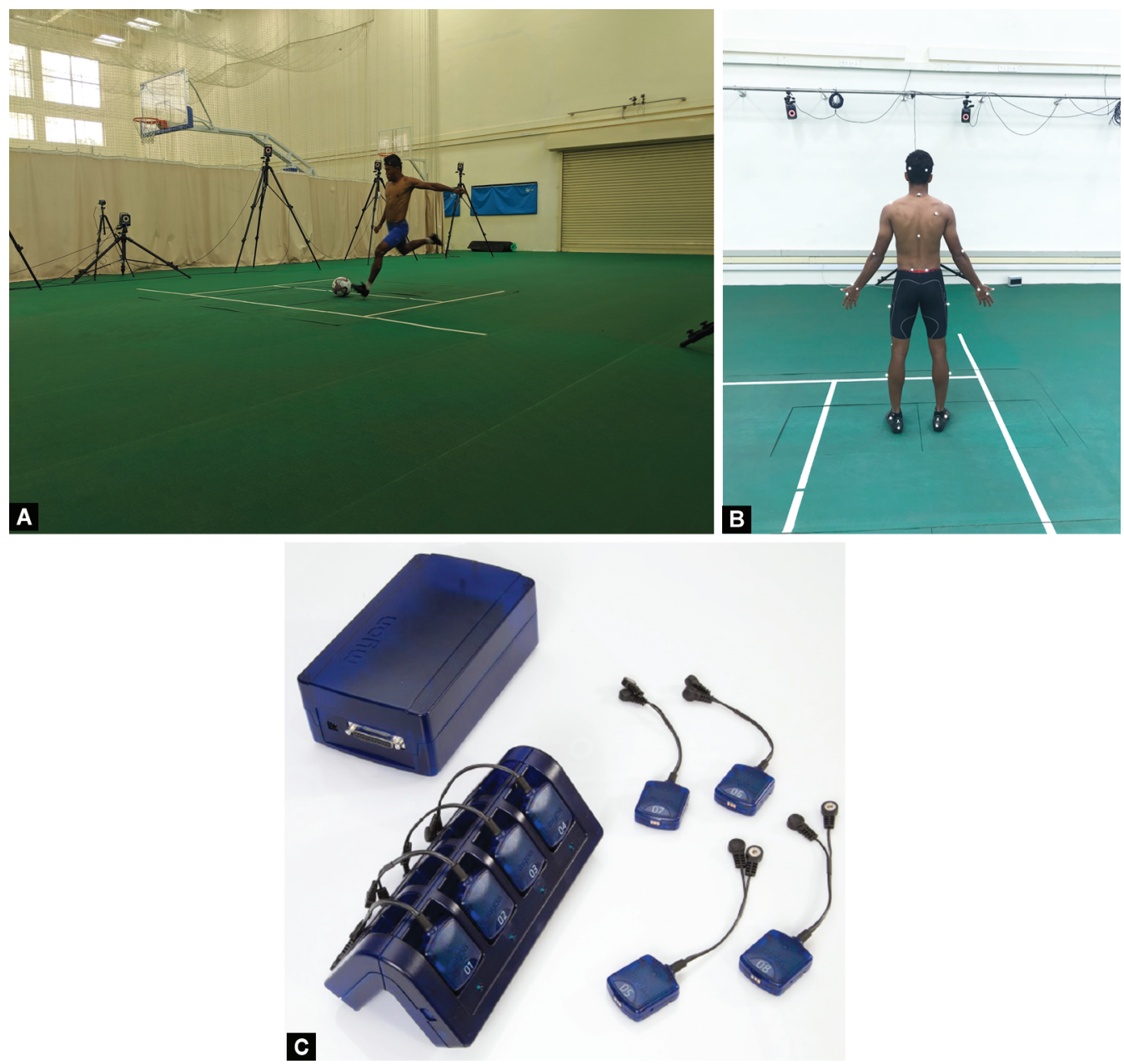

Figs $3 \mathrm{~A}$ to C: Simultaneous 3D motion capture for kinematic analysis along with force plate kinetic analysis and EMG analysis of the football instep kick (Images courtesy: Centre for Sports Science, Sri Ramachandra Institute of Higher Education and Research, Chennai) 
muscle imbalances reduces sports injuries to less than one-third and overuse injuries could be almost halved. ${ }^{43}$ Combination of specific core strengthening exercises with regular soccer training for optimal performance. ${ }^{44}$

\section{Determinants of Successful Return to Play}

While all efforts must be taken to prevent injuries in football, it is also prudent to remember that injuries will keep happening due to the nature of the game itself and other various factors. In the unfortunate event of injury, the following points are generally taken into account to guide the player regarding the timing of return to play after proper management of the injury:

- Type, site, duration of injury also with regards to reinjury status

- Absence of clinical symptoms (applying region-specific scoring systems)

- Appropriate investigation like an ultrasound or any dynamic test that can demonstrate tissue healing

- Injury-specific eccentric muscle strength testing (e.g., Askling $\mathrm{H}$-test for hamstring injury, isokinetic strength using dynamometers)

- Seventy percent of the rehabilitation time completely dedicated to the core and proprioception training

- A biomechanical analysis of football-specific action to test for accuracy and performance

- A customized high-performance assessment tool to grade the step balance, sports-specific parameters like sprinting time/ speed, change of direction speed, yo-yo testing, 1RM leg press, rotational med ball throw distance, vertical and broad jump testing

Table 3: Biomechanical variables measured during a football instep kick and their clinical relevance

\begin{tabular}{|c|c|c|c|}
\hline Category & $\begin{array}{l}\text { Biomechanical } \\
\text { variable }\end{array}$ & Unit & $\begin{array}{l}\text { Clinical } \\
\text { significance }\end{array}$ \\
\hline \multirow[t]{3}{*}{$\begin{array}{l}\text { Upper segment } \\
\text { variables }\end{array}$} & Lateral trunk flexion & $\circ$ & $\begin{array}{l}\text { Lumbar spine } \\
\text { injury }\end{array}$ \\
\hline & $\begin{array}{l}\text { Pelvic shoulder } \\
\text { separation angle at } \\
\text { backswing }\end{array}$ & $\circ$ & $\begin{array}{l}\text { Adductor and } \\
\text { groin injury }\end{array}$ \\
\hline & $\begin{array}{l}\text { Peak trunk rotation } \\
\text { velocity }\end{array}$ & $\% \mathrm{~s}$ & $\begin{array}{l}\text { Spine injury, kick } \\
\text { performance }\end{array}$ \\
\hline \multirow[t]{5}{*}{$\begin{array}{l}\text { Lower segment } \\
\text { variables }\end{array}$} & $\begin{array}{l}\text { Max knee flexion at } \\
\text { acceleration phase }\end{array}$ & $\circ$ & $\begin{array}{l}\text { Knee ligamentous } \\
\text { injury }\end{array}$ \\
\hline & $\begin{array}{l}\text { Max hip extension at } \\
\text { backswing }\end{array}$ & $\circ$ & Groin strain \\
\hline & $\begin{array}{l}\text { Peak hip flexion ve- } \\
\text { locity at leg cocking }\end{array}$ & $\% / \mathrm{s}$ & Hamstring injury \\
\hline & $\begin{array}{l}\text { Support leg knee } \\
\text { flexion at ball contact }\end{array}$ & $\circ$ & $\begin{array}{l}\text { Knee and spine } \\
\text { injury }\end{array}$ \\
\hline & $\begin{array}{l}\text { Ankle plantar flexion } \\
\text { at ball contact }\end{array}$ & $\circ$ & $\begin{array}{l}\text { Ankle } \\
\text { impingement }\end{array}$ \\
\hline \multirow[t]{4}{*}{$\begin{array}{l}\text { Kick cycle-related } \\
\text { variables }\end{array}$} & $\begin{array}{l}\text { Length of last stride/ } \\
\text { step }\end{array}$ & $\mathrm{m}$ & Kick performance \\
\hline & $\begin{array}{l}\text { Poststrike ball } \\
\text { velocity }\end{array}$ & $\mathrm{m} / \mathrm{s}$ & Kick performance \\
\hline & $\begin{array}{l}\text { Duration of each } \\
\text { phase of kick cycle }\end{array}$ & s & Kick performance \\
\hline & $\begin{array}{l}\text { Total duration of kick } \\
\text { cycle }\end{array}$ & $\mathrm{s}$ & Kick performance \\
\hline
\end{tabular}

\footnotetext{
, degrees; $\mathrm{s}$, second; $\mathrm{m}$, meter; ${ }^{\circ} / \mathrm{s}$, degrees per second
}

- Participation in at least five to six normal training sessions with the team without difficulty and having parameters comparable with preinjury data.

\section{Conclusion}

Football is paving its future in India with a greater number of leaguelevel tournaments and international representations happening each year. Performance analysis and characteristic determinants of injury can be obtained by performing a biomechanical analysis of desired action of which kicking is given utmost importance due to increasing incidence of lower limb injuries.

\section{Clinical Significance}

Understanding the key elements of football kicking action from a biomechanical perspective by means of kinematic analysis using 3D motion capture, kinetic analysis using force plate data, and electromyographical analysis and applying it to modify techniques will lead to optimal performance. Also, implications for training strategies can be drawn from these studies in order to prevent injuries and benefit the team as a whole.

\section{ACKnowledgments}

We acknowledge Fédération Internationale de Football Association (FIFA) and the Asian Football Confederation (AFC) for their scientific research papers and guideline documents.

\section{References}

1. FIFA.com. The FIFA/Coca-Cola World Ranking - Ranking Table - FIFA. com [Internet]. www.fifa.com [cited 2020 Apr 18]. Available from: https://www.fifa.com/fifa-world-ranking/ranking-table/men/.

2. Fullenkamp AM, Campbell BM, Laurent CM, et al. The contribution of trunk axial kinematics to poststrike ball velocity during maximal instep football kicking. J Appl Biomech 2015;31(5):370-376. DOI: 10.1123/jab.2014-0188.

3. Wehbe GM, Hartwig TB, Duncan CS. Movement analysis of Australian National League football players using global positioning system technology. J Strength Cond Res 2014;28(3):834-842. DOI: 10.1519/ JSC.0b013e3182a35dd1.

4. Rahnama N, Reilly $T$, Lees $A$. Injury risk associated with playing actions during competitive football. Br J Sports Med 2002;36(5):354-359. DOI: 10.1136/bjsm.36.5.354.

5. Dvorak J, Junge A. Football injuries and physical symptoms. A review of the literature. Am J Sports Med 2000;28(5 Suppl):S3-S9. DOI: 10.1177/28.suppl_5.s-3.

6. Peterson L, Junge A, Chomiak J, et al. Incidence of football injuries and complaints in different age groups and skill-level groups. Am J Sports Med 2000;28(5 Suppl):S51-S57. DOI: 10.1177/28.suppl_5.s-51.

7. Chomiak J, Junge A, Peterson $L$, et al. Severe injuries in football players. Influencing factors. Am J Sports Med 2000;28(5 Suppl):S58S68. DOI: 10.1177/28.suppl_5.s-58.

8. Brophy RH, Backus SI, Pansy BS, et al. Lower extremity muscle activation and alignment during the football instep and side-foot kicks. J Orthop Sports Phys Ther 2007;37(5):260-268. DOI: 10.2519/ jospt.2007.2255.

9. Hägglund $M$, Waldén M, Ekstrand J. Risk factors for lower extremity muscle injury in professional football: the UEFA injury study. Am J Sports Med 2013;41(2):327-335. DOI: 10.1177/0363546512470634.

10. Valle X, Mechó S, Pruna R, et al. The MLG-R muscle injury classification for hamstrings. Examples and guidelines for its use. Apunts Med Esport 2019;54(202):73-79. DOI: 10.1016/j.apunts.2018.11.002.

11. Hägglund $M$, Atroshi I, Wagner $P$, et al. Superior compliance with a neuromuscular training programme is associated with fewer $A C L$ 
injuries and fewer acute knee injuries in female adolescent football players: secondary analysis of an RCT. Br J Sports Med 2013;47(15):974979. DOI: 10.1136/bjsports-2013-092644.

12. Frobell RB, Roos HP, Roos EM, et al. Treatment for acute anterior cruciate ligament tear: five year outcome of randomised trial. BMJ 2013;346(jan24 1):f232. DOI: 10.1136/bmj.f232.

13. Eren OT. The accuracy of joint line tenderness by physical examination in the diagnosis of meniscal tears. Arthroscopy 2003;19(8):850-854. DOI: 10.1016/S0749-8063(03)00736-9.

14. Harris JD, Brophy RH, Siston RA, et al. Treatment of chondral defects in the player's knee. Arthroscopy 2010;26(6):841-852. DOI: 10.1016/j. arthro.2009.12.030.

15. Giza E, Fuller $C$, Junge $A$, et al. Mechanisms of foot and ankle injuries in football. Am J Sports Med 2003;31(4):550-554. DOI: 10.1177/03635465030310041201.

16. Fuller CW, Smith $G L$, Junge $A$, et al. The influence of tackle parameters on the propensity for injury in international football. Am J Sports Med 2004;32(1 Suppl):43S-53S. DOI: 10.1177/0363546503261248.

17. Junge A, Dvořák J. Football injuries during the 2014 FIFA World Cup. Br J Sports Med 2015;49(9):599-602. DOI: 10.1136/bjsports-2014-094469.

18. Bachmann LM, Kolb E, Koller MT, et al. Accuracy of Ottawa ankle rules to exclude fractures of the ankle and mid-foot: systematic review. BMJ 2003;326(7386):417. DOI: 10.1136/bmj.326.7386.417.

19. Werner J, Hägglund $M$, Waldén $M$, et al. UEFA injury study: a prospective study of hip and groin injuries in professional football over seven consecutive seasons. Br J Sports Med 2009;43(13):10361040. DOI: $10.1136 /$ bjsm.2009.066944.

20. Weir A, Brukner $P$, Delahunt $E$, et al. Doha agreement meeting on terminology and definitions in groin pain in players. Br J Sports Med 2015;49(12):768-774. DOI: 10.1136/bjsports-2015-094869.

21. Aspetar Sports Medicine Journal - Risk factors for groin injury during football kicking [Internet]. [cited 2018 Dec 17]. Available from: http:// www.aspetar.com/journal/viewarticle.aspx?id=163\#.XBeqd1wzblU.

22. Esteve $E$, Rathleff MS, Bagur-Calafat $C$, et al. Prevention of groin injuries in sports: a systematic review with meta-analysis of randomised controlled trials. Br J Sports Med 2015;49(12):785-791. DOI: 10.1136/bjsports-2014-094162.

23. Bennell K, Matheson G, Meeuwisse W, et al. Risk factors for stress fractures. Sports Med 1999;28(2):91-122. DOI: 10.2165/00007256199928020-00004.

24. Popp KL, Hughes JM, Smock AJ, et al. Bone geometry, strength, and muscle size in runners with a history of stress fracture. Med Sci Sports Exerc 2009;41(12):2145-2150. DOI: 10.1249/MSS.0b013e3181a9e772.

25. Ekstrand J, Torstveit MK. Stress fractures in elite male football players. Scand J Med Sci Sports 2012;22(3):341-346. DOI: 10.1111/j.16000838.2010.01171.x.

26. Alfredson $\mathrm{H}$. Chronic midportion Achilles tendinopathy: an update on research and treatment. Clin Sports Med 2003;22(4):727-741. DOI: 10.1016/S0278-5919(03)00010-3.

27. Kujala UM, Sarna S, Kaprio J. Cumulative incidence of achilles tendon rupture and tendinopathy in male former elite players. Clin J Sport Med 2005;15(3):133-135. DOI: 10.1097/01.jsm.0000165347.55638.23.

28. Cook JL, Purdam CR. Is tendon pathology a continuum? a pathology model to explain the clinical presentation of load-induced tendinopathy. Br J Sports Med 2009;43(6):409-416. DOI: 10.1136/ bjsm.2008.051193.
29. Roberts EM, Metcalfe A. Mechanical analysis of kicking. Biomechanics 1969;2(3):315-319. DOI: 10.1016/0021-9290(69)90091-8.

30. Willimczik K, Biomechanik der Sportarten. Grundlagen - Methoden - Analysen. Rowohlt Berlin-Verl.; 1989.

31. Hong Y. Routledge Handbook of Ergonomics in Sport and Exercise. Routledge; 2013. p. 608.

32. Shan G, Zhang X. From 2D leg kinematics to 3D full-body biomechanics-the past, present and future of scientific analysis of maximal instep kick in football. Sports Med Arthrosc Rehabil Ther Technol 2011;3(1):23. DOI: 10.1186/1758-2555-3-23.

33. Kellis $E$, Katis A. Biomechanical characteristics and determinants of instep football kick. J Sports Sci Med 2007;6(2):154-165.

34. Shan G, Westerhoff P. Full-body kinematic characteristics of the maximal instep football kick by male football players and parameters related to kick quality. Sports Biomech 2005;4(1):59-72. DOI: 10.1080/14763140508522852.

35. Dörge HC, Andersen TB, Sørensen H, et al. EMG activity of the iliopsoas muscle and leg kinetics during the football place kick. Scand J Med Sci Sports 1999;9(4):195-200. DOI: 10.1111/j.1600-0838.1999.tb00233.x.

36. Lovell GA, Blanch PD, Barnes CJ. EMG of the hip adductor muscles in six clinical examination tests. Physical Therapy in Sport 2012;13(3):134-140. DOI: 10.1016/j.ptsp.2011.08.004.

37. Watanabe K, Nunome H, Inoue K, et al. Electromyographic analysis of hip adductor muscles in football instep and side-foot kicking. Sports Biomech 2018. 1-12.

38. Thorborg K, Krommes KK, Esteve E, et al. Effect of specific exercisebased football injury prevention programmes on the overall injury rate in football: a systematic review and meta-analysis of the FIFA 11 and 11+ programmes. Br J Sports Med 2017;51(7):562-571. DOI: 10.1136/bjsports-2016-097066.

39. Bahr R, Thorborg K, Ekstrand J. Evidence-based hamstring injury prevention is not adopted by the majority of Champions League or Norwegian premier league football teams: the nordic hamstring survey. Br J Sports Med 2015;49(22):1466-1471. DOI: 10.1136/ bjsports-2015-094826.

40. Scase E, Cook J, Makdissi M, et al. Teaching landing skills in elite junior Australian football: evaluation of an injury prevention strategy. Br J Sports Med 2006;40(10):834-838. DOI: 10.1136/bjsm.2006. 025692.

41. Lovell R, Whalan M, Marshall PWM, et al. Scheduling of eccentric lower limb injury prevention exercises during the soccer micro-cycle: which day of the week? Scandinav J Med Sci Sports 2018;28(10):2216-2225. DOI: $10.1111 / \mathrm{sms} .13226$.

42. Finch CF, Twomey DM, Fortington LV, et al. Preventing Australian football injuries with a targeted neuromuscular control exercise programme: comparative injury rates from a training intervention delivered in a clustered randomised controlled trial. Inj Prev 2016;22(2):123-128. DOI: 10.1136/injuryprev-2015-041667.

43. Lauersen JB, Bertelsen DM, Andersen LB. The effectiveness of exercise interventions to prevent sports injuries: a systematic review and meta-analysis of randomised controlled trials. Br J Sports Med 2014;48(11):871-877. DOI: 10.1136/bjsports-2013-092538.

44. Prieske $\mathrm{O}$, Muehlbauer $\mathrm{T}$, Borde R, et al. Neuromuscular and athletic performance following core strength training in elite youth soccer: role of instability. Scandinav J Med Sci Sports 2016;26(1):48-56. DOI: 10.1111/sms.12403. 